British Universities and Medical Schools held in Bristol in July, 1956. We hope to publish our observations as they become available, but in the meanwhile any satisfactory explanation of the differences so far observed between Oxford and Leeds would be most rewarding.I am, etc.,

Leeds, 2.

REFERENCES

S. E. Finlay.

1 Dupertuis, C. W., and Tanner, J. M., Amer. J. phys. Anthrop., 1950, 8 , 27.

2 Parnell, R. W., ibid., 1954, 12, 209

., 1956, 5, 76.

\section{Physique and Medicine}

SIR,-Apropos of a remark in one of your leading articles (Journal, June 29, p. 1520): “Medicine appears to attract those with the same body build that is associated with good all-round achievement in sport and academic life and with the least likelihood of having to consult a general practitioner about mental illness." If so, perhaps this would account for the backwardness of medicine to-day where it comes to the treatment of the whole man rather than the technological manipulation of bits of his anatomy and physiology. Are the physical and mental " hearties" likely to make the best healers ? Or to initiate researches the more likely to prove fertile because based on deeper understanding of those fallible men and women who fall ill ?-I am, etc.,

Haslemere, Surrey.

H. HARRIS.

\section{Nocturnal Enuresis}

SIR,-Mention of successful treatment of nocturnal enuresis by hypnosis in the most interesting articles by Dr. A. Fry (Journal, June 8, p. 1323) and Dr. H. Stewart (p. 1320) has prompted me to describe a new method, simpler than hypnosis, of treating this most troublesome complaint.

I started with the same assumption as Dr. Fry, that removal of worry about bed-wetting and installation of hope of recovery are essential for successful treatment, and decided to test the claims of the makers that "oblivon- $C$ " (methylpentynol carbamate) is a specific for nervous tension by giving it to a series of bed-wetters in my practice. The results, summarized in the table, far exceeded my expectations. Some of the patients had already received psychotherapy without any improvement. The position, however, was considerably changed when methylpentynol carbamate was included as an adjunct to the psychotherapy.

\begin{tabular}{|c|c|c|c|c|c|c|c|}
\hline \multirow{2}{*}{\multicolumn{2}{|c|}{$\begin{array}{c}\text { Age } \\
\text { Distribution } \\
\text { in Years }\end{array}$}} & \multirow[t]{2}{*}{$\begin{array}{l}\text { No. of } \\
\text { Cases }\end{array}$} & \multicolumn{2}{|c|}{$\begin{array}{l}\text { Previous Treatment } \\
\text { (including } \\
\text { Psychotherapy) }\end{array}$} & \multirow[t]{2}{*}{$\begin{array}{c}\text { No } \\
\text { Better }\end{array}$} & \multirow[t]{2}{*}{$\underset{\text { Improved }}{\text { Much }}$} & \multirow[t]{2}{*}{ “Dry" } \\
\hline & & & Yes & No & & & \\
\hline $\begin{array}{l}0-5 \\
5-10 \\
10-20 \\
20+\end{array}$ & $\begin{array}{l}. \\
\because \\
.\end{array}$ & $\begin{array}{l}3 \\
2 \\
4 \\
1\end{array}$ & 2 & $\begin{array}{l}1 \\
2 \\
2 \\
1\end{array}$ & $\bar{z}$ & $\begin{array}{l}1 \\
1\end{array}$ & $\begin{array}{l}\mathbf{1} \\
\mathbf{3}\end{array}$ \\
\hline \multicolumn{2}{|r|}{ s.. } & 10 & 4 & 6 & - & 4 & 6 \\
\hline
\end{tabular}

Two short histories are given for illustration: (1) Male, aged 7: duration of enuresis 12 months; urine analysis, normal. Dose of methylpentynol carbamate, $200 \mathrm{mg}$., three times a day for six weeks. Result: gradual improvement with eventual disappearance of symptoms. The patient remained "dry" over a two-month follow-up. (2) Female, aged 15: a known bed-wetter for 12 months but suspected of having concealed the disability for much longer. Forced to go to the surgery by parents and refused urine analysis. A specimen obtained later, however, was normal. Treatment: sulphafurazole tablets, 2 three times a day; mist. pot. cit., $\frac{1}{2} \mathrm{fl}$. oz. (14 ml.), three times a day ; methylpentynol carbamate, $200 \mathrm{mg}$., three times a day. After six days the sulphafurazole was stopped, but symptoms still persisted. Methylpentynol carbamate was continued, and after three further weeks the symptoms cleared up. This was confirmed by the mother, who inspected the bedding daily. The girl has been symptom-free during a full three-month follow-up period.

Admittedly, this is a small series. But the cases were unselected and the results so good that $I$ felt it worth while to describe them. Methylpentynol carbamate also has the merit of being safe.-I am, etc.,

Leek, Staffs.

G. KAGAN.

\section{Is This a Record ?}

SIR,-Dr. G. I. Watson's experience of a 3-year-old who swallowed a screw (Journal, June 8, p. 1362) prompts me to record a worrying time $I$ had with a 3-year-old girl. She swallowed a 12-sided threepenny-piece on June 14, 1953, at 7 p.m. I saw her two hours later, and as there was nothing abnormal on examination I reassured the mother and arranged to see the child regularly. On June 16, however, she started vomiting everything back, including fluids, and for the first time complained of pain in her throat. I sent her up to the Bromsgrove General Hospital, where Dr. D. I. Harries kindly screened her, and located the coin just below the cricoid. Accordingly I admitted her to the local thoracic unit, where she was examined next day. The report (dated June 18) read as follows: "By now this child will have returned home. We oesophagoscoped her but the threepenny bit proved most elusive and could not be extracted with the forceps. It passed into the stomach, and an $x$-ray, taken yesterday at noon, suggested that it is already in the colon. I have spoken to her mother and told her exactly what the situation is, and, should she be in the least bit worried, we will see the child straight away."

Unfortunately, the surmise that the coin had left the stomach proved over-optimistic; and as the coin had not appeared by June 25 I took her up to see Dr. Harries again for screening. The coin was found lying in the stomach. At my suggestion Dr. Harries agreed to attempt massaging the coin through the pylorus after I had first administered atropine. This failed, so I next tried atropine methonitrate without success, and finally amyl nitrite. Even inhaling from 3-minim (0.2-ml.) capsules proved ineffective, and the refractory coin remained in statu quo. I continued observing the child and reassuring the mother, as the child remained well and happy. On June 29, fifteen days after being swallowed, the coin was passed naturally in a normal stool. The previous day the child had been taken on a Sunday school outing to Barry Island, and had been on the "big dipper." My opinion is that the tremendous excitement or fright might somehow have effected the passage of the coin through the pylorus. I do not know, but I was on the same outing and went on the big dipper myself, and found it a most alarming and hair-raising experience.-I am, etc.,

\section{Bromsgrove, Worcs. \\ Tropical Pulmonary Eosinophilia}

R. A. F. JACK.

SiR,-Dr. A. Wildervanck in his letter (Journal, May 11, p. 1119) on tropical eosinophilia (eosinophilic lung) concludes that it would be desirable to do blood examinations for microfilariae in these cases, while treatment with diethylcarbamazine might be considered. Since April, 1956, I have used the latter drug in the treatment of this condition and have published a preliminary report ${ }^{2}$ of its curative effect in the first ten cases so treated; a final report on a total of 110 cases is in preparation. The result of this study has shown that diethylcarbamazine has a specific action in patients suffering from eosinophilic lung which can be oompared very favourably with that obtained in cases treated with organic arsenicals. Besides symptomatic improvement, clearing of the abnormal radiological picture, and decrease in the elevated erythrocyte sedimentation rate to normality, a distinctive feature is a fall in the circulating eosinophils as occurs with arsenotherapy. This decrease, which begins on the first day of treatment, continues rapidly throughout the first five days and then more gradually till counts below 2,000 eosinophils per c.mm. are finally reached. Three out of 110 cases relapsed, but showed the same response to 
second courses of diethylcarbamazine. There are no significant toxic symptoms with the dosage used, which is $6 \mathrm{mg}$. per $\mathrm{kg}$. body-weight per dose three times a day for a period of five days. Treatment of a further 50 cases has confirmed the earlier findings. In my opinion diethylcarbamazine is a safe and effective drug in the treatment of eosinophilic lung and should replace organic arsenicals, the use of which has sometimes resulted in encephalopathy and death, an unfortunate result in a disease which, although incapacitating, has no mortality in itself.

Blood examinations for microfilariae in patients suffering from this disease have consistently been negative. Out of a group of 150 patients which I observed and reviewed in 1951." nocturnal blood films for microfilariae were negative in the 61 cases examined. Again in the present series of 110 cases, examination of blood samples taken at night, using Knott's concentration technique, failed to reveal the presence of microfilariae. However, in view of the successful therapeutic results obtained with diethylcarbamazine, an antifilarial drug, it was decided to examine the sera of subsequent cases for complement-fixing antibodies using as antigen a $1 \%$ alcoholic extract of dried powder of Dirofilaria immitis according to the method described by Fairley ${ }^{3}$ and Ridley with slight modifications. Positive reactions in high serum dilutions were obtained in all of 12 patients suffering from eosinophilic lung, becoming negative subsequent to treatment. ${ }^{5}$ The filarial complement-fixation test was positive in relatively low titres in only some of the sera from cases of hancrofti and malayi filariasis, and from dogs infected with $D$. immitis, but in 10 patients with mild eosinophilia and pulmonary symptems who were not cases of eosinophilic lung and in 25 healthy controls the test was negative. All of a further 50 patients suffering from eosinophilic lung have shown an initially high filarial complement-fixation test antibody titre with decline after treatment, but at the date of this communication the tests have not yet become negative. In none of these patients was there clinical or parasitological evidence of filariasis.

A human filarial aetiology has been previously advanced for eosinophilic lung on the basis of the histological findings of microfilariae in lymph nodes of a few patients with hypereosinophilia, lymphadenopathy, and pulmonary symptoms, ${ }^{67}$ but valid objections still exist to this hypothesis. True eosinophilic lung, even in cases of fairly long standing, is not accompanied by any of the classical clinical features of filariasis, such as lymphangitis, adenitis, or elephantiasis, nor have microfilariae been demonstrable in blood or sputa of such cases. Conversely, hypereosinophilia is not a usual feature of filariasis, while pulmonary symptoms, although sometimes recorded, ${ }^{8}$ are rare. The clinical pictures of cosinophilic lung and filariasis present reasonably distinct differences. Nevertheless, the aetiological possibility of a filarial infection, not necessarily human, should be considered in view of the response to treatment with diethylcarbamazine, and the finding of sensitivity to filarial proteins in cases of eosinophilic lung.-I am, etc.,

Singapore.

\section{T. J. Danaraj.}

1 Danarai. T. J. Proc. Alumni Ass. Malaya, 1956, 9,172 I. Danarai. T. J. Proc. Alumni Ass. Malaya, 1956, 9, 172.
Eosinophilic Lung. A Study of 150 Cases Seen in Singapore, 1951.
Papineau Studins, Singapore.

3 Fairley. N. H.. Trans roy. Soc. trop. Med. Hyg., 1931, 24, 635.

s Danaraj. T. J.. da Silva. L. S., and Schacher, J. F., Proc. Alumni Ass. Malaya. 1957 13. 109 .

van der Sar. A.. and Hartz, H., Amer. J. trop. Med. Hyg. 1945, 25, 83.

Friess. J.. Pierrou. M., and Segalen, J., Bull. Soc. Path. exot., 1953, 46.

- Rifkin, H.. and Eherhârd, T. P., Ann. intern. Med., 1946, 25, 324.

\section{Specd Warning Device}

SIR.-The letter from Mr. William Gissane, of Birmingham (Journal, July 6, p. 46), is interesting but leads me to suggest that he cannot be old enough to remember the earlier days of motoring, the days of the model " $T$ " Ford, when thirty miles an hour was fast and forty was speeding. A device said to be popular in America then showed a red light on the dashboard at forty miles an hour and played "Nearer, my God, to Thee" at fifty.-I am, etc., Ches:er. D. T. Dickinson.

\section{Compulsive Swearing}

SIR,-The case of Gilles de la Tourette's syndrome described by Dr. R. P. Michael (Joürnal, June 29, p. 1506) is of particular interest, because, so far as I am aware, it is the first published account of the treatment of tics by carbon-dioxide inhalation. It is notable that fifty years ago Meige and Feindel ${ }^{1}$ recorded in their classic monograph on the treatment of tics that the inhalation of chloroform and ether was of some avail, and it therefore seems relevant to question whether the mode of action of these gases is similar.

Dr. Michael's hypothesis that there may be a self-perpetuating process in the genesis of tics, coprolalia, and echolalia by which the muscular and vocal discharges themselves provide the stimulus for a further discharge, is original but does not explain the many clinical features of tics. My own impression, based on a study ${ }^{2}$ of a large number of child tiqueurs, is that the stimulus for the motor discharge is generated by the underlying psychological and possibly physiological tension occurring in certain constitutionally predisposed individuals. I am surprised that Dr. Michael's patient showed no change in tic-frequency under stress, and wonder whether there was in fact any evidence of increased tension during the recording sessions.

Dr. Michael's postulate that carbon dioxide alters the plasma hydrogen-ion concentration, and thereby lowers the excitability of the synapse, might explain the symptomatic improvement resulting from interruption of the hypothetical self-perpetuating system. Thinking along similar lines, I attempted to investigate experimentally ${ }^{3}$ whether tics in childhood are associated with neuromuscular hyperexcitability. The results were inconclusive, but if the hypothesis is correct it is conceivable that carbon dioxide may act by raising the threshold of excitability. However, I should have thought it more likely that the beneficial effect of carbon-dioxide inhalation in the case described was due to the discharge of tension. Whatever the mechanism, I hope that Dr. Michael's article will stimulate further research on the value of carbon dioxide in the treatment of tics.-I am etc.,

Barnehurst, Kent.

DAVID M. ZAUSMER.

REFERENCES

1 Meige, H., and Feindel, E. C. L., Tics and Their Treatment, 1907. Appleton, London.

2 Zausmer, D. M., Arch. Dis. Childh., 1954, 29. 537.

s Ann phys. Med., in press.

\section{Slippery Hospital Floors}

SIR,-Unfortunately the craze for "spit and polish" still exists in some hospitals, in spite of the occurrence of fractures among members of the administrative and nursing staffs from falls on slippery floors, often made more slippery by the use of the " bumper." Convalescent patients should be accompanied by an attendant when first out of bed, and encouraged to walk bare-foot, thereby getting a sense of position in space: the firmness of the cold floor giving a feeling of security and confidence, thereby diminishing the risk of faintness or falling.-I am, etc.,

London. W.1.

B. Whitchurch Howell.

\section{Post-maturity}

SIR,- - May I be permitted to use a few lines of your valuable space to make a few comments on Professor F. J. Browne's interesting article, "Foetal Post-maturity and Prolongation of Pregnancy" (Journal, April 13, p. 851), particularly as several of the quoted hospital report figures $(F, M$, $\mathrm{N}, \mathrm{O}$, and $\mathrm{P}$ ) are concerned with our teaching obstetrical units at the University of Capetown?

The majority of the patients admitted to our institutions, apart from hospital $O$ and part of $F$, were non-white (Bantu and coloured), more than $20 \%$ of whom were non-booked, of a very poor type, and living under conditions of extreme poverty, and a large proportion of whom suffered from chronic ill-health-i.e., pre-eclampsia, eclampsia, antepartum haemorrhage, etc. It should also be mentioned that the high foetal and maternal mortality occurring in hospital $\mathbf{P}$ (almost entirely non-white and largely non-booked) was 